\title{
Participant-driven photo-elicitation in library settings: A methodological discussion
}

\author{
Shailoo Bedi, Jenaya Webb
}

\begin{abstract}
With the current attention in libraries on user-focused services and spaces, there is an increased interest in qualitative research methods that can provide insight into users' experiences. In this paper, we advance photo-elicitation-a research method that employs photographs in interviews - as one such method. Although widely used in the social sciences, photo-elicitation has seen comparatively little uptake in Library and Information Studies (LIS). Here, we provide an overview of the method, consider epistemological and theoretical approaches, discuss cases of its application in library contexts and examine the benefits of using photoelicitation for LIS research. We draw on our own research experiences and argue that photo-elicitation is a productive method for learning about the lived experiences of our users and for creating a collaborative approach to library research.
\end{abstract}

\section{Introduction}

Massive national and international projects such as the National Student Survey (NSS) in the UK and the National Survey on Student Engagement (NSSE) in North America are indicative of the desire across the higher education community to know more about students' experiences. However, the notions of student engagement and experience are incredibly complex. As Bryson (2014) notes, these large-scale surveys "do not uncover the richness and diversity of the student experience, or very much about the perspective of students.” (p. 7). Kahu (2013)

\section{Authors}

Shailoo Bedi hold a $\mathrm{PhD}$ in Education and works for the University of Victoria as the Director, Academic Commons and Strategic Assessment.

Email: $\underline{\text { shailoo@uvic.ca }}$

Jenaya Webb is a Public Services and Research Librarian at the University of Toronto.

Email: jenaya.webb@utoronto.ca

Received 20 February 2017

Accepted 8 May 2017 
calls for the use of qualitative methodologies to build a more holistic understanding of the complexity of "the dynamic process that is student engagement" (p. 769). Priestner and Borg (2016) argue that, with the current attention in libraries on user-focused services and spaces, Library and Information Studies (LIS) researchers must explore qualitative research methods that can provide new insights into the complexity of our users' experiences. In this article, we argue that participatory visual research methods can help support this kind of qualitative, user-focused learning.

Photo-elicitation is a research method that employs photographs in interviews. In this paper, we focus on participant-driven photo-elicitation (PDPE) techniques, where research participants are asked to take photographs in order to document their first-hand experiences in particular settings. The participant's photographs are then discussed during an interview with the researcher in order to construct a shared understanding of the participant's experience. We believe that by using visual research methods, researchers' understanding of user experience will be made more meaningful, as these methods offer a level of depth that is not easily afforded through surveys, questionnaires and focus groups.

As librarian researchers and practitioners, we both recently conducted photoelicitation studies to investigate users' experiences in our library spaces. Our work using participatory visual methodologies inspired this paper, which aims to provide an overview of the method and make a case for its applicability in library research. We explore its historical foundations and examine the methodological variations, theoretical assumptions and epistemologies with which it is associated. We then survey the LIS literature and discuss the application of photographic methods to the study of libraries and library users. We identify four key benefits of photo-elicitation for library research: (a) it encourages collaborative research, (b) it allows for new and unexpected insights from research participants, (c) it supports discussion about abstract concepts and (d) it facilitates the interview process. We then discuss ethical considerations.

We argue that participant-driven photo-elicitation is a productive visual method for gaining unique insights into the lived experiences of library users and for setting a collaborative research agenda for libraries. Ultimately, we hope this paper will expand the case for participatory photographic methods in library settings and contribute to the scholarly conversation around visual methods in LIS research.

\section{Photo-elicitation: An overview}

Photo-elicitation is one of many types of visual research methods in use across the sciences and social sciences disciplines alike. Visual research covers a huge range of techniques and approaches and can include "collecting, producing, organizing, and interpreting imagery in all its various forms for research purposes" (Pollak, 2017 , p. 98). Visual methods also incorporate a wide variety of types of images 
including drawings, maps, photographs, digital media and videos (see Knowles \& Cole, 2008; Pauwels, 2015; Pink, 2007; Prosser, 1998; Rose, 2012).

Visual research methods appear to be gaining popularity in LIS. However, several LIS scholars engaged in visual research have argued that a strong methodological discourse surrounding visual methods is still lacking in our discipline (Hartel, Lundh, Sonnenwald \& Foster, 2012; Pollak, 2017).

\subsection{Background}

The work most commonly referenced as an early example of photo-elicitation is anthropologist John Collier's 1957 article "Photography in anthropology: A report on two experiments". Collier describes two experiments, one of which compared a photo interview (using photographs he made of his field site) with a regular (non-photo) interview. He noted several key differences between the two techniques, indicating that the photo interviews resulted in more detailed and concrete information, helped prompt the participant's memory and also eased nervousness on the part of the research subject. He explains, "the pictures served as a second subject; both interviewer and informant fastened their attention on the pictures, which relieved the strain of being questioned directly" (p. 849). He also noted that the photos played a role in structuring the interview and keeping the subject "on track", meaning that some of the subject's thoughts and reflections may have been lost without the photos (p. 849).

Since Collier's article was first published, the method has been adapted and employed productively across research disciplines in a wide range of contexts and using a diversity of techniques. Researchers in social sciences have long recognized the value of photographs in conducting interviews and the current disciplinary breadth of the method's application displays its great versatility and growing popularity. Photo-elicitation has been used to explore the experience of NGO field workers in international development (Shankar, 2016), teachers' perceptions of school children (Stockall \& Davis, 2011), patient experiences in healthcare (e.g. Fritz \& Lysack, 2014; Kantrowitz-Gordon \& Vandermause, 2016), land management practices (Kong et al., 2015), outdoor adventure experiences (Loeffler, 2004), studying sport and exercise (Curry, 1986; Mills \& Hoeber, 2013) and customer behaviour in a retail context (Petermans, Kent \& Van Cleempoel, 2014). These studies are just a few examples of a vast and growing cross-disciplinary literature.

\section{$2.2 \quad$ Terminology}

Researchers interested in visual methods will find a range of approaches to using photographs in the interview context. Pink (2007) identifies three of the key ways that researchers use photographs in interviews: (a) using photographs made by the interviewer, (b) using the interviewees' own collection of photographs and (c) using photographs taken by the interviewee specifically for the purpose of the research. The last type, where researchers hand over the camera to their participants to create the photos, participatory photo-elicitation, is the focus of this article. 
Our survey of the literature revealed a diversity of terms associated with participatory photo-elicitation techniques, including, among others, photovoice (e.g. Julien, Given \& Opryshko, 2013; Click, 2014), photo diaries (e.g. Gabridge, Gaskell \& Stout, 2008; Keller, 2012; Gratz \& Gilbert, 2011), photo survey (e.g. Briden, 2007), photo-narrative (e.g. Prosser, 1998) and photo interviews (e.g. Vila, 2013). Though the distinctions among these techniques may often be subtle, they signify differences in the way the method is used. For example, the photo diary method used by Gabridge, Gaskell and Stout (2008) included journal-style note-taking, where other methods did not. Additionally, the terminology used is important because it often reflects the epistemological and theoretical approach of the researcher. For instance, Vila (2013) uses the term photo-interviewing rather than photo-elicitation in order to challenge the word elicitation, which, he argues, creates the idea that the research can simply elicit or extract ideas from participants.

Pollak (2017) articulates what we see as an important distinction related to terminology. She groups visual methods into two categories based on who creates the images: participatory methods (where the participants themselves create the images) and non-participatory methods (where the researcher creates and/or collects the images). She writes, "if we consider ... how images are used to gather, create, and embody knowledge, authorial perspective becomes the primary dividing line" (p. 100). Although examples of non-participatory visual methods exist in LIS, participatory methods provide an important insiders' view and an emic perspective that we believe is vital in understanding student experiences in library settings. Thus, we use the term participant-driven photo-elicitation (PDPE) broadly to encompass participatory methods and to focus on those where research participants, not researchers, create the photographs used in interviews.

\section{$2.2 \quad$ Benefits}

As Rose (2012) notes, photo-elicitation has a number of "enthusiastic advocates" across the social sciences (p. 317). Indeed, many studies that employ photoelicitation methods dedicate some discussion in their publications to the benefits and the productivity of the method (Briden, 2007; Buck, 2016; Clark-Ibáñez, 2004; Haberl \& Wortman, 2012; Harper, 2002; Van Auken, Frisvoll \& Stewart, 2010; Vila, 2013). Meo (2010, p. 155) offers a comprehensive list of the advantages of photo-interviews over traditional oral interviews (structured or semi-structured) that are applicable to LIS researchers:

a) they elicited longer and more enjoyable interviews;

b) they enhanced the participation and control of interviewees;

c) the gathering of richer data about similar topics;

d) they reinforced what was already stated in the traditional interview;

e) they offered a closer look at what and whom participants considered important;

f) they allowed the emergence of unexpected topics; and 
g) they enabled making sense of some data, which otherwise would have been difficult to interpret.

The versatility and documented productivity of photo-elicitation across a breadth of disciplines suggests that photo-elicitation holds promise for in-depth studies that could offer a richer understanding of users' experiences in library contexts as well.

\section{Epistemologies}

Photographs are used in many research settings in many different ways.

Therefore, as with any research approach, researchers must consider their own epistemological approaches to shape the use of methods. Our approach to PDPE falls directly in the qualitative research paradigm. Prosser and Swartz (1998) emphasize that, just as in any undertaking of qualitative research, when using visual material as part of the research process, researchers' underlying epistemological and methodological assumptions must be considered, as these determine the way research is conducted. Furthermore, as researchers, we both identify as constructivists, interpretivists and subjectivists in our philosophical orientations: we believe that some forms of knowledge are socially constructed, open to interpretation and therefore subjective.

We see photo-elicitation as a tool that can provide insight into the ways that different people make meaning. Schwartz (1989) argues that the creator of the photo as well as the viewers (including the researcher) actively construct meaning and that nothing about the image, even the reception of it, is passive. In addition, researchers who take this approach often refer to photo-elicitation as polysemic, suggesting that it can generate multiple meanings on multiple levels (Barthes, 1977; Schwartz, 1989; Pink, 2003, 2007). Byers explains that an image such as a photograph is not simply the message; rather, it is "raw material for an infinite number of messages" that the creator and the viewer can use to construct meaning for themselves (1966, p. 31). Liebenberg (2009) adds, "how images are created and the sense viewers make of them depends fundamentally upon cultural assumptions, personal knowledge, and the context in which the picture is generated and presented", noting that "how images are seen and read is shaped by the values, beliefs, assumptions, and experiences" (p. 445) that both participant and researcher will bring with them.

When used in this reflective manner, PDPE can provide a way for researchers and participants to discuss images created by participants, thereby situating the participants as authorities on their lives and experiences and allowing them more control of the research content (Liebenberg, 2009). In other words, using a photoelicitation methodology allows the participant to be in the "driver's seat".

According to Harper (2002), when research participants actively reconstruct their reality through images in the research process, they use a "powerful medium to help the researcher understand their reality" (p. 140). This suggests that experiences and meanings become more tangible through visual representation and may be understood in ways that other conventional forms of communication may not allow. In this way, images may facilitate participant articulation of lived realities in a manner that better aligns research results with participants' lives. But 
it is also important to keep in mind that the images from photo-elicitation occupy both symbolic and literal roles. Photographs of objects can create multiple meanings for the taker of the image, as well as for the viewer. As such, the photos cannot be seen as stand-alone data in the research process; rather, the photos are combined with an interview process to elicit more data that is reflective of user experience (Liebenberg, 2009).

\section{Theoretical approaches}

Positioning visual research within a theoretical framework is vital for the interpretation and analysis of images. Drawing on theoretical frameworks can also help us reflect on our own positions as librarians and researchers to consider how we might find new ways to give voice to the experiences of our users and communities and to understand their experiences at a deeper level.

One theoretical framework that has been applied to visual methods is the critical education put forward by Paulo Freire (1970). Within his work, Freire proposed that images could serve as one tool to enable members of a community to reflect back their everyday realities in order to critically investigate their lives, environments, and spaces and form a shared dialogue around strategies for change. Wang and Burris $(1994,1997)$ took up Freire's approach in their development of the photovoice method. The three goals they describe for this visual method are: "(1) to enable people to record and reflect their community's strengths and concerns, (2) to promote critical dialogue and knowledge about important issues through large and small group discussion of photographs and (3) to reach policymakers" (1997, p. 370). Julien, Given and Opryshko (2013) also draw on this theoretical framework, in a library setting, in their use of photovoice to explore undergraduate students' perceptions of information literacy.

Scholars have also linked PDPE methods with feminist theory, a literature that suggests that minority voices are often marginalized by dominant perspectives. In the case of studies regarding libraries, it can be argued that librarian perspectives, professional judgment and, in essence, the librarian voice are more dominant. Applying a feminist theory perspective to data analysis of photos through a visual research method such as photo-elicitation aids in reframing the librarian researcher's position and allowing the more marginalized voices to take centre stage (see Julien, Given \& Opryshko, 2013).

Depending on how a researcher understands photos and how the research is framed, a project may require a distinct method of analysis. With photo-elicitation studies, researchers can employ qualitative analysis methods, such as grounded theory, thematic analysis or content analysis. Researchers also diverge in their analytical strategy regarding whether photos will be analysed in addition to interview transcripts or simply used in the interview process to gather deeper understanding of participants' motives, perceptions or psychological states.

Using visual methods like photo-elicitation can seem deceptively simple.

Although photographs may appear to provide clear representations of research participants' experiences, this is rarely the case. There are many considerations in using images in research, one of the primary ones being that photographs are not neutral: they are contextual, intentional products (Pink, 2003, 2007). Goldstein 
(2007) provides an excellent overview of the complexities of images as data and points out that, "every photograph results from a series of choices" (p. 74). In other words, no photograph represents an objective version of "truth". Rather, it represents the technical, aesthetic and emotional decisions of the photographer (Goldstein, 2007). By using photographs in conjunction with interviews, as in methods such as photo-elicitation, photo narrative and photovoice, researchers can begin to unpack these complexities and understand participants' intentions.

All types of academic research, regardless of methodology, raise questions regarding the objectivity/subjectivity of the researcher. Within some research paradigms, such as those that fall in the quantitative realm, researchers typically advocate for objectivity and emphasize a neutrality with the research-in essence for the researcher to be an "outsider" to the research being conducted (Dwyer \& Buckle, 2009). Others argue that researchers cannot be outsiders (or neutral in the research process), given that they determine the research question and design and thus ultimately implement the approach and analyse the data (Creswell, 2013; Charmaz, 2006; Harper 2002; Schwartz, 1989). Given this dynamic, some scholars believe it is acceptable to be seen as an insider to the research and to declare one's biases, position and subjectivities (Charmaz, 2006). As librarians conducting research on our practice and with intimate ties to our physical space, resources and services, we see ourselves as "insiders"; any notion of neutrality or objectivity associated with being an outsider does not exist in our research perspective.

\section{Participant-driven photo-elicitation as a strategy of inquiry in LIS}

In LIS literature, we are seeing an emergence of studies that employ ethnographic methods, among them some visual methods, to engage with students to better understand their experience. Ethnographic methods such as interviews and participant observation have become increasingly common in library research and have begun to form what Khoo, Rozaklis and Hall (2012) call a "coherent and emerging research genre that uses ethnographic methods to investigate libraries, their users, wider social contexts, and the relationships between these phenomena" (Khoo, Rozaklis, \& Hall, 2012). Additionally, ethnographic methods have become the foundation for several large, well-known user studies focused on improving library services and spaces (Duke \& Asher, 2012; Foster \& Gibbons, 2007) and communities of researchers, such as the UX Libs community, have focused on ethnographic methods to address user experience in the library context (see Priestner \& Borg, 2016).

Many of these studies include visual methods. Photographs can be employed both as a methodology (the approach that shapes the entire research design) or one tool used to gather data while attached to other research methodologies, including case study, narrative inquiry, phenomenological studies, action research and many others (Collier \& Collier, 1986; Harper, 2002; Pink, 2007). When used as a research tool, photographs can add depth and help to corroborate and triangulate data. The incorporation of photographic methods adds a richness to these ethnographic studies and provides glimpses into parts of the student experience 
that researchers may not otherwise see. Writing specifically about the use of photo surveys in the Rochester project, Briden notes, "images and interviews pulled together various facets of being an undergraduate student at the University of Rochester that were previously unknown to us and made them real and cohesive" (Briden, 2007, p. 47).

In addition to large-scale ethnographic projects such as these, librarian researchers have begun to apply photo-elicitation methods in various contexts. This section considers how photo-elicitation has been applied in library settings; it shows the method being used to examine users' experiences in library spaces, to inform renovation projects, to advocate for user-centered instructional design and to learn about students' practices outside immediate library settings. The articles discussed demonstrate a range of uses of the method and are valuable sources of information for researchers considering its application in their own libraries. Moreover, the studies mobilize many of the same research tools, including photo prompts, interview questions, recruitment tools, consent forms and transcription guidelines. See Briden, 2007; Buck, 2016; Haberl \& Wortman, 2012; Neurohr \& Bailey, 2016; and Newcomer, Lindahl and Harriman, 2016 for examples of research tools.

This section is intended not as a comprehensive review, but as an outline of initial themes related to uses of photographic methods for library research and present examples of the application of photographic methods in use in libraries. (Please see Appendix A for the literature search strategy.)

\subsection{Photographic methods for studying information-seeking activities}

LIS researchers are using photo-elicitation to explore how students seek out the information they need (in physical and virtual spaces) for their studies. Gabridge, Gaskell and Stout (2008) use a method they call photo diaries to examine the information-seeking behaviours of undergraduate and graduate students at MIT. Researchers asked students to document their academic activities over the course of a week using photographs, screenshots and notes about their informationseeking activities. They then brought their photo diaries to an interview with the researchers to unpack their experiences and practices. The photo diary method is similar to other photo-elicitation approaches in that the photographs and screenshots serve as a tool during follow-up interviews. In this case, however, students were also asked to document their activities in a written journal form. The researchers note that, in addition to being an effective method for addressing their research questions, the photo diary method led to new and unexpected findings - such as the lack of student awareness about library services and the day-to-day barriers students faced in accessing them - that were shared across the MIT Libraries system (Gabridge, Gaskell \& Stout, 2008).

Buck (2016) applied photo-elicitation to examine information seeking behaviours with a different group of students: distance education students. While many studies are dedicated to factors related to success in retention and completion of online programs, Buck notes that little is known about how distance students "actually engage in their study environments because there are few opportunities to observe them there" (p. 137). Buck asked her participants to document (with screenshots and photographs) their study habits by making at least 10 images per 
week guided by prompts and questions. She conducted three interviews with each participant over the course of the semester, during which the students shared their images and discussed their experiences. Buck's use of photo-elicitation led to some key revelations about the practices of distance students when it comes to the barriers they face using library resources and helped identify library service gaps for this group. Buck also expands on the benefits of the method explaining that "the use of images helps prompt participants' memory and so participants are more likely to offer more detailed descriptions and show the exact failure or points of success in their research" (p. 158).

\subsection{Photo-elicitation for studying users experience in library spaces}

Photo-elicitation methods have also proven effective for the study of users' immediate experiences in library spaces. In their 2012 article, Haberl and Wortman examine users' experiences in five Edmonton Public Library (EPL) branches. Their research was conducted as part of the EPL's Business Plan initiative and sought to inform recommendations for library renovations and future projects. To gain a deeper understanding of users' needs and desires related to EPL spaces, researchers provided participants with prompts asking them to photograph their favourite and least favourite places in the library, as well as place(s) they liked to spend time with others and places they found inspiring. Haberl and Wortman's use of PDPE in combination with other methods provided their report with a depth that would have been missed with questionnaires and space counts alone. They state, "The interviews and photo-elicitation conducted at EPL provided the researchers with both literal and figurative pictures of participants' perceptions of their library and its spaces and how they use them" (p. 14). In the EPL case, the photo-elicitation results provided tangible data about how users perceive the library, which helped supplement other methods used in the research.

Other researchers who have used photo-elicitation to understand users' experience in library spaces include Lin and Chiu (2012), who explore students' preferences when it comes to functional and aesthetic elements of their library spaces; Neurohr and Bailey (2016), who use photo-elicitation to look into the particular experiences of Native American students in the library at Oklahoma State University; and Newcomer, Lindahl and Harriman (2016), who use photoelicitation as part of a large mixed-methods approach to informing renovations. Newcomer, Lindahl and Harriman found the method particularly useful as a way to generate new ideas for library spaces by uncovering "new and unfamiliar aspects of user needs" (p. 18).

In our own research, we use PDPE methods to investigate users' library wayfinding strategies and shed light on students' experiences in library spaces (Bedi \& Webb, 2017). The insights we gained have already begun to inform renovation plans and signage improvements to our physical spaces. For example, a goal of one of our studies was to understand how students were (or were not) using library signage. Through photo-elicitation interviews, participants were able to point to and describe specific signs, confusing terminology and locations where signs were lacking. For example, several students in a study at the University of Toronto photographed the directional sign pictured in Figure 1. During follow-up 
interviews, these participants explained that (among other things) the sign was located on the wrong side of a pillar and was thus not easily visible. Additionally, they noted that "WEST SIDE" was not a useful directional prompt inside a building, especially given that this was the only sign they encountered that used cardinal directions. This type of spatial and object-specific insight can easily be implemented in the creation and replacement of confusing signage to improve student experience.

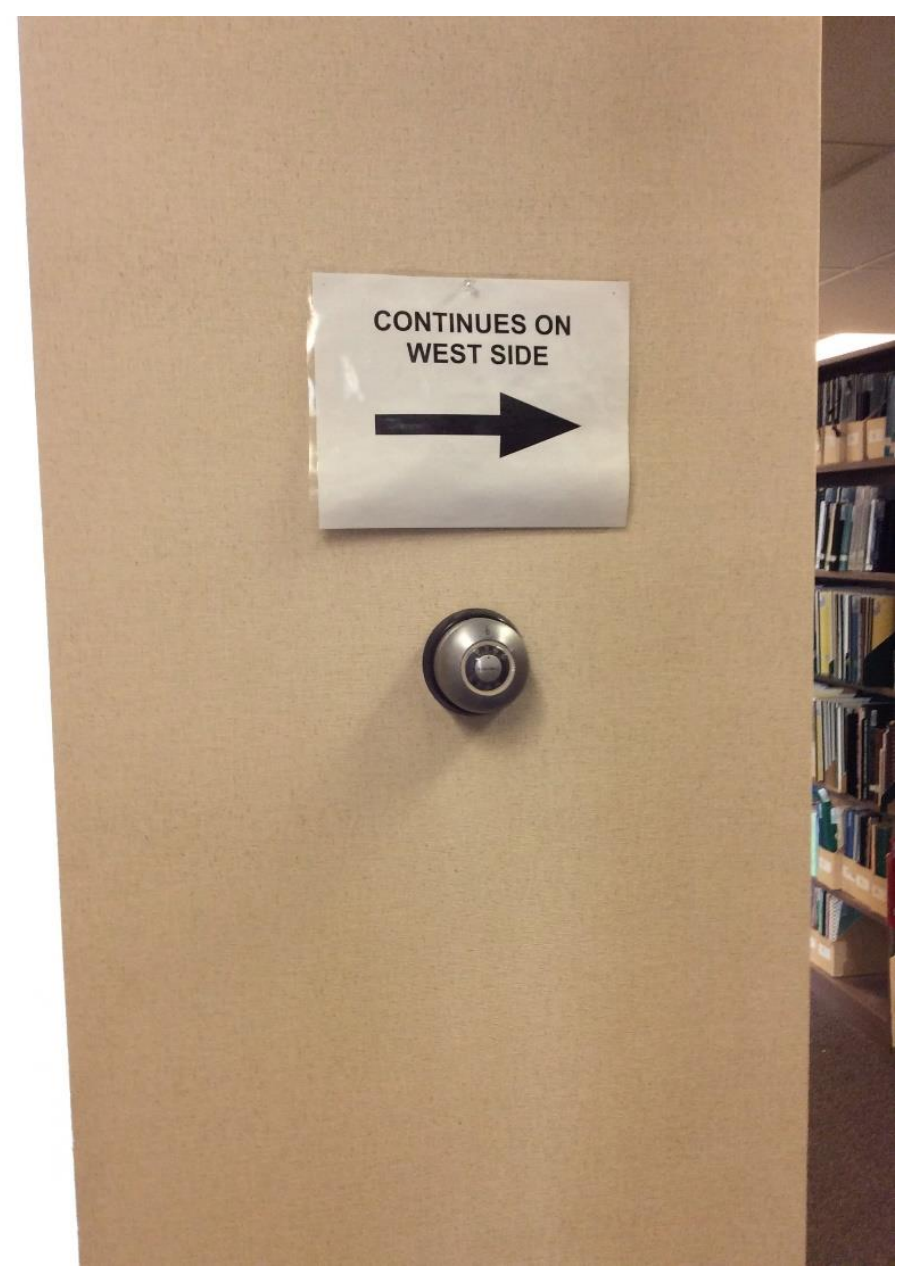

\section{Figure 1. Participant's photograph from the wayfinding study at the University of Toronto.}

Another study within our research pointed toward other changes that could be made to improve student experience of libraries' physical spaces. The photo in Figure 2 shows a student creating a workspace at a chair by a photocopier just so he could plug in to a power source on the wall. Clearly, this is not an ideal workspace, but accessing power is very important for the working needs of students today. This photo and accompanying interview, along with others examples from a study at the University of Victoria, helped to create a case for funding the addition of more outlets in the UVic Libraries. 


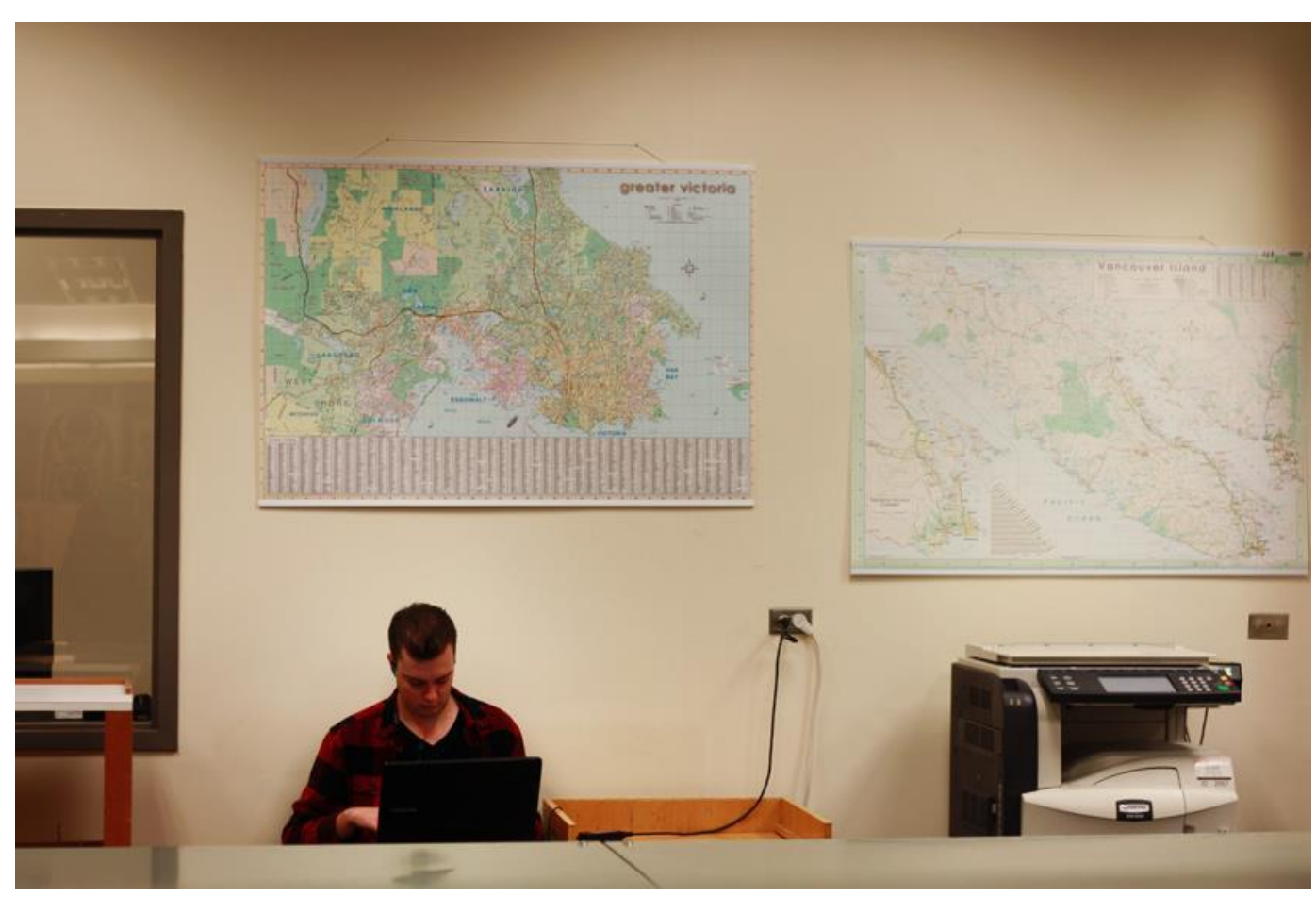

Figure 2. Participant's photograph from the space use study at the University of Victoria.

\subsection{Using photovoice to foreground research participants' voices}

Photovoice is similar to photo-elicitation in that it draws on photographs taken by research participants to drive the interview process. However, photovoice expands on photo-elicitation by incorporating a strong advocacy ethic and by using research results for community development. It thus falls within the strong tradition of action research, which, as Rose describes, "is not just to study something, but to engage research participants and researchers in a process of social learning, analysis, and empowerment, in hope of changing the social situation itself' (Rose, 2012, p. 305). Although it has not been widely applied in the LIS context (Luo, 2017), photovoice helps researchers engage participants as collaborators in the process and bring their voices to bear on decisions regarding library services and spaces.

In their 2013 article, Julien, Given and Opryshko used photovoice as part of a mixed-methods approach to exploring students' perceptions of information literacy — and its connection to their academic success - during their transition from high school to university. The researchers' goal was to create a more student-focused approach to information literacy instructional design, so they gave cameras to students to capture their views of their experiences and the information challenges they faced both inside and outside the library. Researchers also recognized key benefits of photovoice that we believe overlap with photoelicitation methods: (a) both methods facilitate the interview process by providing memory prompts and (b) both methods empower participants "to choose those images they think are worthy of capturing ... and worthy of discussion" (p. 261). By using photovoice, the researchers felt they captured robust data about their 
students' perceptions, which they were able to incorporate into their curriculum design.

Another study from the LIS literature that employs photovoice outside of the library setting is Lloyd and Wilkinson (2016). It uses photovoice to better understand the experiences, information needs and information literacy practices of refugee youth in Australia as they navigate the information ecosystem in their new country. Photovoice was used with focus groups to help address the language barrier since English was not the participants' first language. Lloyd and Wilkinson argue that by making photographs, participants were able to "visually capture information or representations that reflected their understanding of what information was meaningful to them" (p. 303). Additionally, researchers found that the photovoice technique helped connect the idea of information literacy practices with everyday spaces and activities, as the photographs provided insight into where information-seeking happens, both inside and outside of formal educational settings.

\section{Benefits of photo-elicitation methods for library research}

With the attention in libraries on user-focused services and spaces, we see tremendous potential for the use of PDPE in LIS research. Photo-elicitation gives researchers new ways to ask questions and allows them an opportunity to fully develop what we know about library users. There are numerous examples in the literature touting the benefits of photo-elicitation methods in various contexts, including the work of Cox and Benson (2017), Meo (2010), Torre and Murphy (2015) and Van Auken, Frisvoll and Stewart (2010). Based on our own research experiences as well as our survey of the LIS literature, we identify below four key benefits for applying photo-elicitation in library studies: (a) it encourages collaborative research, (b) it allows for new and unexpected insights from research participants, (c) it supports discussion about abstract concepts and (d) it facilitates the interview process.

\subsection{Photo-elicitation encourages collaborative research}

The most important benefit we experienced in our own research, which is also reflected in the literature, is that photo-elicitation allows library users and library researchers to engage in a more collaborative research process. With PDPE in particular, participants are in the position of deciding which photos to take, and as a result, which aspects of their experience to discuss in the follow-up interviews. The discussion of the images is important; the images' meaning is subjective, produced via a collaborative process between researchers and participants (Liebenberg, 2009). In other words, the meanings that images hold for participants are revealed, discussed and developed in the interview process. Pink (2003) reinforces the value of collaborative approaches (as compared to observational approaches) when she writes, "a collaborative approach demonstrates how many aspects of experience and knowledge are not visible; and even those that are visible will have different meanings to different people" (p. 190).

Participants also take on a new role in data collection when they create the images used in the process. In her study of information behaviours among distance 
students, Buck (2016) explains that "students become active participants in the research study, taking photos and screenshots and annotating their images, which allows students to speak with their own voice rather than an observer interpreting what he or she sees" (p. 141). In any researcher-participant situation, there is often a power dynamic that privileges the researcher, who embodies the role of the expert, while participants are the objects of study. But in Buck's case, and many others described above, researchers are not present when the photos are taken, and decisions about which photos to take become the role of the research participant; photo-elicitation informants are thus more active in the research process (Kaplan, 2008).

\subsection{Photo-elicitation allows for new, unexpected insights}

Many studies that use photo-elicitation in library contexts use participantgenerated images. With this technique, participants are provided with some guidelines (often in the form of tasks or questions) but are given cameras and left to make photographs without the presence of the researcher (see Briden, 2007; Buck, 2016; and Newcomer, Lindahl \& Harriman, 2016 for examples of photo tasks and questions). By asking participants to make the photographs, researchers encourage them to consider why they make the images they do and to reflect on what is important to them about each photo. In other words, the participants decide what is important to photograph and take up in the interview. Reflection in an interview, using the photos "means that participant narratives are more representative of how they themselves interpret their context, relationships, decisions and realities" (Liebenberg, 2009, p. 442). This active role for participants can be absent in other research methods, such as surveys, where the researchers determine which specific questions will be asked and which limited topics will be addressed. Photo-elicitation thus gives us, as researchers and library insiders, the chance to challenge our assumptions by seeking to understand an outsider's view and to revise our own ideas about how students experience the library.

Another way that photo-elicitation can provide new insights, is by providing a window into users' experiences beyond the library. Briden (2007), Gabridge, Gaskell and Stout (2008) and Buck (2016) all asked research participants to take cameras outside of the library into other study spaces where they worked. Photoelicitation helped shed light on parts of students' lives that researchers would otherwise be unable to access. Briden (2007) notes that the photo-elicitation findings from the Rochester project helped address researchers' questions and also provided information that was unexpected. She writes, "we were surprised to discover how willing students were to show us and tell us about their lives" ( $p$. 45). Likewise, Buck gained unexpected insights into the day-to-day challenges that distance students face as well as details about the spaces and tools they use to keep organized and how they motivate themselves to complete their distance courses (Buck, 2016).

\subsection{Photo-elicitation supports discussion about abstract concepts}

Photographs are useful stimuli for research participants during interviews. They can help prompt participants to recall particular situations and elicit discussion 
about more abstract ideas. As Julien, Given and Opryshko (2013) explain, photographs in interviews are productive as "points for discussion about the meanings and significances that the participants attach to the documented activities or objects" (p. 257). Lin and Chiu (2012) applied photo-elicitation methods to dig into several extremely abstract concepts such as library users' sensory perceptions, aesthetic preferences and social interactions in libraries. Although these authors concluded that more study was needed, photo-elicitation proved an effective method for starting discussions about users' layered experiences in physical spaces (Lin \& Chiu, 2012). In their examination of refugee youths' information seeking needs, Lloyd and Wilkinson (2016) note that photovoice allowed "participants to represent aspects of their everyday life that are often difficult to articulate (e.g. what types of information are important to them, where they find it)" (p. 303).

In our own research, we noted that participants reflected broadly on their experience in our library spaces. These detailed discussions would not have been possible using research tools such as or surveys or even traditional interview methods. For instance, Figure 3, showing a participant's photo of a library bulletin board, prompted a discussion of the value of print poster space even in the digital signage era.
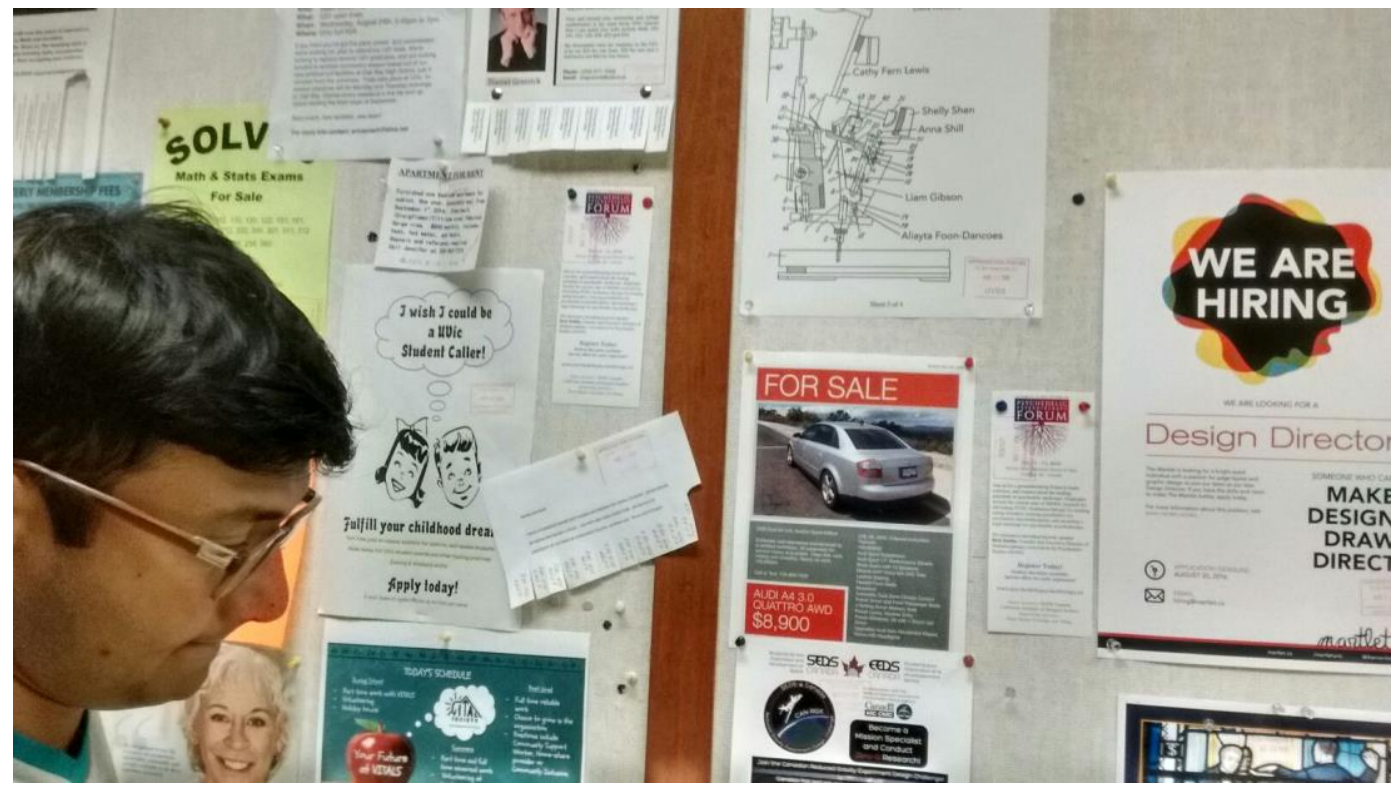

Figure 3. Participant's photograph from the space use study at the University of Victoria.

\subsection{Photo-elicitation can facilitate the interview process}

Scholars across various disciplines have described the use of photos in interviews as good icebreakers for the interview conversation (Epstein et al., 2006; Harper, 2002; Hurworth, 2003; Meo, 2010). As Collier (1957) has explained, integrating photos into the interview allows both the researcher and the participant to focus on the image versus putting the research participant on the spot as the sole object of the study. In our research, we also found that photo-elicitation had the practical 
benefit of facilitating an ease of conversation. Having photos to guide our interviews meant that we only had to ask simple, open-ended questions, such as "What is happening in this photo?" to have meaningful discussions (Bedi \& Webb, 2017). Similarly, in their study in the Edmonton Public Library system, Haberl and Wortman (2012) note that the method allowed the researchers to "more easily build a rapport with the participant", a particular benefit for researchers who may not have extensive research interview expertise (p. 14).

In our own research, we found that photographs can help facilitate in-depth discussions in other ways. In particular, we heard from several participants who described the process of making photographs as a way to overcome intimidating language barriers that would otherwise deter them from participating in the research (Bedi \& Webb, 2017). This finding leads us to hypothesize that photoelicitation may be a tool that can help encourage broader participation from international students on our campuses, leading to the inclusion of more diverse opinions and experiences in library research (Bedi \& Webb, 2017).

The use of photographs in research also reflects broader social trends toward using photographs as a means of communication. Many (though certainly not all) of our users live and work in cultures where images (generated through ubiquitous technologies such as cell phones and shared through social media channels such as Instagram) play a vital role in how people represent themselves, document their lives and communicate their realities. Van Auken, Frisvoll and Stewart (2010) suggest that researchers should leverage this focus on the visual: "If people understand their world more and more through images, using graphical representations as stimuli for reflection would seem to be a logical development in social science research and participatory planning" (p. 373). As Meo (2010) notes, "images help to engage participants in conversation and to respond to them without vacillation because of the familiarity of taking and talking about photos" (p. 150). Indeed, photographic methods present a tremendous opportunity for LIS researchers to use technologies with which our users are comfortable to engage them in a discussion about libraries.

\section{Critical approaches and ethical considerations}

One of our goals with this article is to advocate for the use of participatory photographic methods in library settings. However, we recognize that despite the potential benefits outlined above, challenges remain in implementing such methods in any research setting. This section examines some key considerations for researchers.

\subsection{The image is only part of the picture}

Although it is tempting to see photographs as stand-alone data, in PDPE the focus is on the discussion and the collaborative understanding that the researcher and participant reach in their discussion of the photos. Shankar (2016) cautions the researcher from falling into the positivist trap of seeing an image as being concrete and objective. How we as librarian researchers understand the photograph may be different than how the creator intended; thus, the interview elicitation process is critical. Important insights also emerge from the detail that 
comes to light about what was happening just before and right after the image was taken.

Social science researchers also stress that photographs are not exclusive sources of evidence that can be consulted in lieu of other substantive data (Pink, 2003, 2007; Schwartz, 1989; Weber, 2008). It is in the combination of photos with additional data-gathering methods that photos have the potential to provide insights that enrich a study or provide new avenues of exploration. Schwartz (1989) cautions that researchers should not treat an image as a natural (rather than symbolic) event; otherwise we will fail to consider the author's intentions and meanings.

\subsection{The notion of participant empowerment}

One important benefit often connected to participatory photo methods is that they facilitate a more collaborative research process and can even shift power from the researcher to participants (Julien, Given \& Opryshko, 2013; Rose, 2012). However, as Pollak (2017) notes, "although participatory visual methods are seen as a way of neutralizing to some extent the power differential between researcher and participant ... it is generally understood that the researcher cannot be removed from the facilitation process entirely" (p. 102). For example, in our own research, we imposed constraints on our participants, including providing photo survey tasks, determining the equipment used, setting timelines and describing the purpose of the research project (Bedi \& Webb, 2017). Undoubtedly these actions shaped how our participants engaged in the research process and reinforced the power of the researcher to determine what photographs participants ought to take.

\subsection{Ethical considerations}

There are also important ethical considerations that face researchers who use PDPE. These include ensuring clear and thorough communication around participant consent, intellectual property rights, confidentiality and anonymity. In the case of photo-elicitation where the participant is asked to take the photos, the intellectual property for the image is with the research participants. Thus the participants are not able to be anonymous in the research process. Participants who are concerned about anonymity may decide not to participate, and as researchers we may have a smaller pool of participants. Also, taking photos is an active data creation process, which, although it can be engaging, may put some participants off because it can be time consuming; as a result, recruitment of participants can be difficult (Clark-Ibáñez, 2004).

When using photo-elicitation, researchers need to inform and train participants how to take photos that do not identify others. Participants must either avoid taking photos that include others or use photo release permission forms. As a result of the potential for bystanders to be included in images, participants need to be aware and respectful of privacy concerns that might arise during the course of data collection.

\subsection{Data management and analysis}


Finally, one practical limitation of participatory photo methods is that they can be time consuming, particularly with respect to data management and analysis. Our own research yielded, in one study, 533 photographs taken by participants and 536 minutes of interview recordings in one study, and, in another, 479 images and 423 minutes of interview recordings (Bedi \& Webb, 2017). Because PDPE yields two types of data: photographic data and interview data, additional time is required for analysis. Thus, the data analysis phase can be overwhelming. As Pollak (2017) notes, "visual data can often be easily collected in great quantities, but it is complex, difficult, and time consuming to analyze" (p. 104). As we have discussed, participant-generated images can only be understood within the context of the descriptions of the image produces, the participants. Researchers must consider how they will integrate images into their analysis process and whether the tools they use (such as qualitative data analysis software) can accommodate images or image files. Moreover, Pauwels (2015) suggests that researchers using methods such as PDPE should consider analyzing participants' images "above and beyond the interpretations and rationalizations of their producers" (p. 127). For instance, some researchers may want to conduct basic content analysis of the images in addition to any other analysis they may perform as part of the interview analysis.

\section{Conclusion}

As libraries strive to provide more user-focused spaces and services, there is an increased need to adopt qualitative research methods that can provide in-depth insights into users' experiences. In this paper we have surveyed the literature and drawn on our own research experiences to put forward an argument for participatory photo methods as research methods that can help address this need.

We have provided an introduction to PDPE that we believe will support librarian researcher-practitioners interested in further exploring the method as a way to gain deeper understandings of their own libraries and library users. Ultimately, we hope this paper will have the effect of inspiring librarian researcher-practitioners to engage their library users in a more collaborative approach to research in our field. Putting participants in the position of making the images to be used in the interview reshapes the relationship between researcher and participant into a collaborative process. As libraries aim to provide more user-focused services and spaces, positioning users as collaborators in research is vital.

\section{References}

Barthes, R. (1977). Rhetoric of the image. In R. S. Heath (Trans.), Image-MusicText / Roland Barthes: Essays selected and translated by Stephen Heath (pp. 3251). New York: Hill and Wang.

Bedi, S. \& Webb, J. (2017). Through the students' lens: Photographic methods for research in library spaces. Evidence Based Library and Information Practice, 12(2), 15-35. doi:10.18438/B8FH33 
Briden, J. (2007). Photo surveys: Eliciting more than you knew to ask for. In N. F. Foster \& S. Gibbons (Eds.), Studying students: The undergraduate research project at The University of Rochester (pp. 40-47). Chicago, IL: Association of College and Research Libraries.

Buck, S. (2016). In their own voices: Study habits of distance education students. Journal of Library \& Information Services in Distance Learning, 10(3/4), 137173. doi:10.1080/1533290X.2016.1206781

Bryson, C. (2014). Clarifying the concept of student engagement. In C. Bryson (Ed.), Understanding and developing student engagement (pp. 1-22). New York: Routledge.

Byers, P. (1966). Cameras don't take pictures. Columbia University Forum, 9, 2731.

Charmaz, K. (2006). Constructing grounded theory: A practical guide through qualitative analysis. Los Angeles, CA: Sage Publications.

Clark-Ibáñez, M. (2004). Framing the social world with photo-elicitation interviews. American Behavioral Scientist, 47(12), 1507-1527.

doi:10.1177/0002764204266236

Click, A. (2014). Taking something that is not your right: Egyptian students' perceptions of academic integrity. Libri: International Journal of Libraries \& Information Services, 64(2), 109-123. doi:10.1515/libri-2014-0009

Collier, J. (1957). Photography in anthropology: A report on two experiments. American Anthropologist, 59(5), 843-859. doi:10.1525/aa.1957.59.5.02a00100

Collier, J., \& Collier, M. (1986). Visual anthropology: Photography as a research method (Revised edition). Albuquerque: University of New Mexico Press.

Cox, A., \& Benson, M. (2017). Visual methods and quality in information behaviour research: The cases of photovoice and mental mapping. Information Research, 22(2), paper 749. Retrieved from http://InformationR.net/ir/222/paper749.html

Creswell, J. (2013). Qualitative inquiry and research design: Choosing among five approaches $\left(3^{\text {rd }}\right.$ ed.) Thousand Oaks, CA: Sage Publications.

Curry, T. J. (1986). A visual method of studying sports: The photo-elicitation interview, Sociology of Sport Journal, 3(3), 204-216. doi:10.1123/ssj.3.3.204

Duke, L. M., \& Asher, A. D. (Eds.) (2012). College libraries and student culture: what we now know. Chicago, IL: American Library Association. 
Dwyer, S. C., \& Buckle, J. L. (2009). The space between: On being an insideroutsider in qualitative research. International Journal of Qualitative Methods, 8(1), 54-63. doi:10.1177/160940690900800105

Epstein, I., Stevens, B., McKeever, P., \& Baruchel, S. (2006). Photo elicitation interview (PEI): Using photos to elicit children's perspectives. International Journal of Qualitative Methods, 5(3), 1-11. doi:10.1177/160940690600500301

Foster, N. F., \& Gibbons, S. (Eds.) (2007). Studying students: The undergraduate research project at the University of Rochester. Chicago, IL: Association of College and Research Libraries.

Freire, P. (1970). Pedagogy of the oppressed. New York, NY: Herder and Herder.

Fritz, H., \& Lysack, C. (2014). 'I see it now': Using photo elicitation to understand chronic illness self-management/L'usage de la méthode de photointerview pour mieux comprendre l'autogestion des maladies chroniques, The Canadian Journal of Occupational Therapy, 81(4), 247-255.

doi:10.1177/0008417414540517

Gabridge, T., Gaskell, M., \& Stout, A. (2008). Information seeking through students' eyes: The MIT photo diary study. College \& Research Libraries, 69(6), 510-523. doi:10.5860/crl.69.6.510

Goldstein, B. M. (2007). All photos lie: Images as data. In G. C. Stanczak (Ed.), Visual research methods: Image, society and representation (pp. 54-83). Thousand Oaks, CA: Sage Publications.

Gratz, A., \& Gilbert, J. (2011). Meeting student needs at the reference desk. Reference Services Review, 39(3), 423-438. doi:10.1108/00907321111161412

Haberl, V., \& Wortman, B. (2012). Getting the picture: Interviews and photo elicitation at Edmonton Public Library, LIBRES: Library and Information Science Research Electronic Journal, 22(2), 1-20. Retrieved from http://www.libresejournal.info/492/

Harper, D. (2002). Talking about pictures: A case for photo elicitation, Visual Studies, 17(1), 13-26. doi:10.1080/14725860220137345

Hartel, J., Lundh, A., Sonnenwald, D., \& Foster, N. F. (2012). State of the art/science: Visual methods and information behavior research. Proceedings of the Association for Information Science and Technology, 49(1).

doi:10.1002/meet.14504901009

Hurworth, R. (2003). Photo-interviewing for research. Social Research Update, 40(1), 1-4. Retrieved from http://sru.soc.surrey.ac.uk/SRU40.html 
Julien, H., Given, L. M., \& Opryshko, A. (2013). Photovoice: A promising method for studies of individuals' information practices. Library and Information Science Research, 35(4), 257-263. doi:10.1016/j.lisr.2013.04.004

Kahu, E. R. (2013). Framing student engagement in higher education. Studies in Higher Education, 38(5), 758-773. doi:10.1080/03075079.2011.598505

Kantrowitz-Gordon, I., \& Vandermause, R. (2016). Metaphors of distress: Photoelicitation enhances a discourse analysis of parents' accounts. Qualitative Health Research, 26(8), 1031-1043. https://doi.org/10.1177/1049732315575729

Kaplan, E. A. (2008). Global trauma and public feelings: Viewing images of catastrophe. Consumption Markets \& Culture, 11(1), 3-24.

doi:10.1080/10253860701799918

Keller, A. (2012). In print or on screen? Investigating the reading habits of undergraduate students using photo-diaries and photo-interviews, Libri: International Journal of Libraries \& Information Studies, 62(1), 1-18. doi:10.1515/libri-2012-0001

Khoo, M., Rozaklis, L., \& Hall, C. (2012). A survey of the use of ethnographic methods in the study of libraries and library users. Library \& Information Science Research, 34(2), 82-91. doi:10.1016/j.lisr.2011.07.010

Knowles, J. G., \& Cole, A. L. (Eds.). (2008). Handbook of the arts in qualitative research: Perspectives, methodologies, examples, and issues. Los Angeles, CA: Sage Publications.

Kong, T. M., Kellner, K., Austin, D. E., Els, Y. \& Orr, B. J. (2015). Enhancing participatory evaluation of land management through photo elicitation and photovoice. Society \& Natural Resources, 28(2), 212-229. doi:10.1080/08941920.2014.941448

Liebenberg, L. (2009). The visual image as discussion point: Increasing validity in boundary crossing research, Qualitative Research, 9(4), 441-467. doi:10.1177/1468794109337877

Lin, Y-C., \& Chiu, M-H. (2012). A study of college students' preference of servicescape in academic libraries, Journal of Educational Media \& Library Sciences, 49(4), 609-636. Retrieved from http://joemls.dils.tku.edu.tw/detail.php?articleId=49405\&lang=en

Lloyd, A., \& Wilkinson, J. (2016). Knowing and learning in everyday spaces (KALiEds): Mapping the information landscape of refugee youth learning in everyday spaces. Journal of Information Science, 42(3), 300-312.

doi:10.1177/0165551515621845 
Loeffler, T. A. (2004). A photo elicitation study of the meanings of outdoor adventure experiences. Journal of Leisure Research, 36(4), 536-556.

Luo, L. (2017). Photovoice: A creative method to engage library user community. Library Hi Tech, 35(1), 179-185. doi:10.1108/LHT-10-2016-0113

Meo, A. I. (2010). Picturing students' habitus: The advantages and limitations of photo-elicitation interviewing in a qualitative study in the city of Buenos Aires. International Journal of Qualitative Methods, 9(2), 149-171. Retrieved from https://journals.library.ualberta.ca/ijqm/index.php/IJQM/article/view/6682

Mills, C., \& Hoeber, L. (2013). Using photo-elicitation to examine artefacts in a sport club: Logistical considerations and strategies throughout the research process, Qualitative Research in Sport, Exercise and Health, 5(1), 1-20. doi:10.1080/2159676X.2012.712989

Neurohr, K. A., \& Bailey, L. E. (2016). Using photo-elicitation with Native American students to explore perceptions of the physical library. Evidence Based Library and Information Practice, 11(2), 56-73. doi:10.18438/B8D629

Newcomer, N. L., Lindahl, D., \& Harriman, S. A. (2016). Picture the music: Performing arts library planning with photo elicitation. Music Reference Services Quarterly, 19(1), 18-62. doi:10.1080/10588167.2015.1130575

Pauwels, L. (2015). Reframing visual social science: Towards a more visual sociology and anthropology. Cambridge: Cambridge University Press.

Petermans, A., Kent, A., \& Van Cleempoel, K. (2014). Photo-elicitation: Using photographs to read retail interiors through consumers' eyes. Journal of Business Research, 67(11), 2243-2249. doi:10.1016/j.jbusres.2014.06.012

Pink, S. (2003). Interdisciplinary agendas in visual research: Re-situating visual anthropology. Visual Studies, 18(2), 179-192.

doi:10.1080/14725860310001632029

Pink, S. (2007). Doing visual ethnography: Images, media, and representation in research ( $2^{\text {nd }}$ ed.) London: Sage Publications.

Pollak, A. (2017). Visual research in LIS: Complementary and alternative methods. Library and Information Science Research, 39(2), 98-106.

doi:10.1016/j.lisr.2017.04.002

Priestner, A., \& Borg, M. (Eds.) (2016). User experience in libraries: Applying ethnography and human-centred design. New York, NY: Routledge.

Prosser, J. (Ed.) (1998). Image-based research: A sourcebook for qualitative researchers. London: Taylor \& Francis. 
Prosser, J., \& Schwartz, D. (1998). Photographs within the sociological research process. In J. Prosser (Ed.), Image-based research: A sourcebook for qualitative researchers (pp. 101-115). London: Taylor \& Francis.

Rose, G. (2012). Visual methodologies: An introduction to researching with visual materials ( $3^{\text {rd }}$ ed.) Thousand Oaks, CA: Sage Publications.

Schwartz, D. (1989). Visual ethnography: Using photography in qualitative research. Qualitative Sociology, 12(2), 119-154. doi:10.1007/BF00988995

Shankar, A. (2016) Auteurship and image-making: A (gentle) critique of the photovoice method. Visual Anthropology Review, 32(2), 157-166.

doi:10.1111/var.12107

Stockall, N. \& Davis, S. (2011). Uncovering pre-service teacher beliefs about young children: A photographic elicitation methodology. Issues in Educational Research, 21(2), 192-209. Retrieved from http://www.iier.org.au/iier21/2011conts.html

Torre, D., \& Murphy, J. (2015). A different lens: Using photo-elicitation interviews in education research. Education Policy and Analysis Archives, 23(111), 1-26. doi:10.14507/epaa.v23.2051

Van Auken, P. M., Frisvoll, S. J., \& Stewart, S. I. (2010). Visualising community: using participant-driven photo-elicitation for research and application. Local Environment: The International Journal of Justice and Sustainability, 15(4), 373388. doi:10.1080/13549831003677670

Vila, P. (2013). The importance of photo-interviewing as a research method in the study of identity construction processes: An illustration from the U.S.-Mexico border. Visual Anthropology, 26(1), 51-68. doi:10.1080/08949468.2013.735187

Wang, C. \& Burris, M. A. (1994). Empowerment through photo novella: Portraits of participation. Health Education \& Behavior, 21(2), 171-186.

doi:10.1177\%2F109019819402100204

Wang, C. \& Burris, M. A. (1997). Photovoice: Concept, methodology, and use for participatory needs assessment, Health Education \& Behavior, 24(3), 369-387.

doi:10.1177\%2F109019819702400309

Weber, S. (2008). Visual images in research. In J. G. Knowles \& A. L. Cole, (Eds.). Handbook of the arts in qualitative research: Perspectives, methodologies, examples, and issues (pp. 42-54). London: Sage Publications. 


\section{Open access and copyright}

Library and Information Research is an open access journal. A freely available copy of this paper may be downloaded from the journal's website:

http://www.lirgjournal.org.uk

Copyright and associated moral rights in works published in Library and Information Research are retained by the author(s) but this paper may be used freely, with proper attribution, in educational and other non-commercial settings. 